JSCMT

Journal of Sustainable Construction

Materials and Technologies

J. Sustain. Construct. Mater. Technol. 3(1) (2018) 156-162
Journal of Sustainable

Construction Materials and Technologies

http://www.eds.yildiz.edu.tr/jscmt

\title{
Investigating High-Speed Railways In Terms Of The Economy For Our Country and The Region
}

\author{
Onur Şahin ${ }^{1, a, *}$, Mehmet Fatih Altan ${ }^{1, b}$ \\ ${ }^{1}$ Faculty of Engineering, Istanbul Aydin University, Florya Campus, Istanbul, Turkey

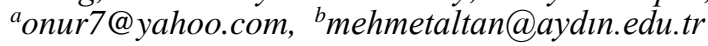

Received June 6, 2017; accepted September 4, 2017

\begin{abstract}
High-speed railways have a history of more than 40 years. Railways continued to be popular especially in various parts of Eastern Europe and Asia until the end of the 1980s. As of today, we can talk about a high-speed railway that continues to develop in the continents of Africa, Asia and the Americas around the world. At this point, one of the most significant factors in railways, in particular high-speed railways, is planning. Planning determines the effect of the railway on the economy, as well.

Within this scope, with the proper planning of transportation investments, our country and the region at the center of which our country is located will be able to achieve an integrated development in the economy.
\end{abstract}

Keywords: Economy, Planning, Transportation Investments, Passenger Transportation, High-Speed TrainIntroduction

\section{Introduction}

The railways have started to become widespread again, particularly with the development of high-speed railways under the leadership of France and Germany. With the effective involvement of Spain in this process, we now can talk about a high-speed rail network throughout the European continent. The railway in Japan on the other hand has had an uninterrupted development for long years. Recently, in the far east, several countries, especially China, South Korea and Taiwan, have also been actively involved in this process.

The railways gained worldwide acceptance again, particularly as of the 1990s. In the case of our country, significant investments were made in the railways during the last period of the Ottoman Empire and during the first years of the Republic. However, interest in railways remained quite low until the early 2000s. Starting from the 2000s, serious investments have been made in our country in the railways, particularly in the high-speed railways and urban rail systems, and have continued increasingly ever since [1].

* Corresponding author.

E-mail address: onur7@yahoo.com (O.

Şahin) https://doi.org/10.29187/jscmt.2018.19 


\section{Course of the Transportation Investments in Our Country}

Transportation investments have an important and vital role in economic and social terms. Transportation complements many different disciplines. Almost half of the budget allocated for investments in our country has come to be allocated for transportation. High-speed railways, on the other hand, are one of the most active modes of transportation connecting the cities, territories, countries and regions. One of the most significant advantages of the railways is that it is more environment-friendly than other modes of transportation. At this point, one of the most significant factors in railways, in particular high-speed railways, is planning. Planning determines the effect of the railway on the economy, as well.

Within this scope, with the proper planning of transportation investments, our country and the region at the center of which our country is located will be able to achieve an integrated development in the economy. In the last decades, Turkey has achieved important economic and industrial developments. With a population of more than 79 million, the country has $63230 \mathrm{~km}$ of highways and $15000 \mathrm{~km}$ of railways. The highways account for $91 \%$ of freight transportation and $95 \%$ of passenger transportation. The railway has an average share of $4 \%$ in freight and passenger transportation, with the remaining percentages being shared by sea and air transportation [1].

While railway investments in Turkey were made over a wide geography with the center being Anatolia during the Ottoman Period (the Hejaz Railway), they were spread throughout Anatolia to a large extent by the Founding Fathers during the Republic Period, despite the limited conditions at the time. In the following years, both our country and the world socio-politics faced spread of the road transportation mode and the use of automobiles. This is also a result of the Cold War Period and the Capitalistic Polarization.

In the end, Turkey was also gravely affected by this process. Unfortunately, the productivity and technical participation process during the first years of the Republic could not be supported with balanced distribution and growth in every area in the subsequent years. An indicator of this is also reflected in our failure to achieve a balanced distribution of Road-Rail-Sea transportation.

\section{Developing a Train Planning Model}

This rail network includes different train capacities, as well as single or multiple tracks on multiple platforms. Within this scope, decreasing the fuel consumption costs constitutes the satisfaction criteria for the railway companies and reduction of the total trip time is evaluated as the travel satisfaction criteria. Public rail transport planning is a highly comprehensive work. It is based on the interoperation of numerous elements that need to be managed simultaneously. The planning process is generally divided into several steps depending on the magnitude of traffic systems of the rail system public transport. Within this scope, the planning process is basically divided into tactical planning and strategic planning, of which strategic planning is composed of demand analysis, line planning and train planning. The tactical planning process starts with the train planning, and the subsequent steps in this level of planning are catenary set planning, personnel planning and personnel assignment [2].

In this context, firstly, passenger demand is evaluated and analyzed. Consequently the quantity of passengers demanding to be transported from a certain departure point to a certain arrival point is calculated. After that, line planning is made, which covers decisions on the frequency of operation of specific lines or routes. Then, in the train planning step, all departure and arrival times of the line are calculated. At the same time, an entire planning process is divided into three steps: strategic, tactical and operational planning. The relevant structure is detailed in Table 1 . Efficiency of a service means measuring the demand for the relevant service through satisfaction. Under the scope of such works, efficiency and effectiveness are regarded as criteria representing the viewpoints of the operator (the railway company) and the user (passenger group), respectively [3]. 
Table 1. Levels of Planning [3]Stages of Planning

\begin{tabular}{|l|l|l|}
\hline & Time Period & Target \\
\hline Strategic Level & $5-15$ years & Acquisition of resources \\
\hline Tactical Level & $1-5$ years & Allocation of resources \\
\hline Operational Level & 24 hours-1 year & Daily planning \\
\hline
\end{tabular}

Train planning constitutes one of the most challenging and important problems in rail planning, which has caught the attention of the researchers for decades. The physical rail network is shared by numerous trains, and in fact requires coordinated use of the suitable resources. Besides, simultaneous planning of passenger and freight trains has a significant effect on the level and quality of service offered to the public.

The multi-purpose approach generally yields better planning alternatives; the main reason for this is the possibility to evaluate many related factors as the targets for the planning, as well as the possibility to evaluate the same in different units. In this context, good working practices have been produced for transportation networks, traffic management, airline service planning, bus operation planning, airline flight planning, freight train planning, urban school bus planning, public transport network design, transport investment planning, airline personnel assignment, transport and assignment problems, passenger train service planning, air network design and vehicle planning problems [4].

Any time frame analyzed from the train planning problem is required to meet three types of main constraints: continuity constraints, travel time and waiting time constraints and safety constraints. The rest of the calculation is related to formulation of these constraints. This part of the formulation is to a large extent available in the current literature. However, due to the comprehensive nature of the formula and for purposes of convenience, it will be beneficial to re-perform detailed analysis of the same for each study [5].

In any rail network, all physical nodal points such as junctions, level crossings and stations carry a line. Headway constraints at these nodal points allow travel of only a single train in a specific time frame in any line. However, at some nodal points allocated as more than one incoming and outgoing line in a rail network, headway constraints do not allow for the possibility of encounter of trains travelling in the same or opposite directions.

\section{The Example of Europe in Reducing The Environmental Impacts of High-Speed Trains}

The most prominent keywords about eco-friendly approaches are energy saving and lowering noise levels. In order to follow the national and therefore European Union (EU) requirements and strengthen the eco-friendliness of the European railway traffic, railway companies and manufacturers are gathering more and more each day to evaluate their works in this area.

A travel speed current of approximately $280 \mathrm{~km} / \mathrm{h}$ trigger significant levels of noise, due to which it should be avoided to differentiate current in trains, since it also reduces aerodynamic strength of the train. Bogie coatings lead to both lowered aerodynamic strength and sporadic aerodynamic noises resulting from high levels of turbulence in the bogie area. Similarly, air flow line of the pantograph frame structure also ensures reducing the noise generated at high speeds [6].

Different national railway companies come together with the aim of solving basic areas of research, in order to follow the European Union (EU) acquis and strengthen the eco-friendly nature of the European rail traffic. Furthermore, the European Rail Research Advisory Council (ERRAC) has identified the Strategic Rail Research and Innovation Agenda (SRRA), and has started to work in the field of environment [7]. 
Since technical solutions are developed based solely on the specific conditions of the national rail system, these may not be compliant with the national rules of other countries; the researches concerned shed light on the given problems, and demonstrate a clear international approach in many cases.

The tendency to increase in speed in rail traffic seems to continue without interruptions. The future production of high-speed trains (HST) will have maximum operating speeds of over $350 \mathrm{~km} / \mathrm{h}$. This future development of the rail traffic can only be affected on the economic basis if environmental acceptability is given sufficient consideration [8].

\section{General Railway Trends in The World}

Rail companies in Europe carry out major studies to meet the public demand for the rail traffic which has a low impact on the environment. Noise production and transformation stages, as in the energy consumption, have been dealt with in various projects together with professionals from the European rail contractors and manufacturers. Joint research projects provide a general knowledge base and strongly support the harmonization of existing national legislation and guidelines for train design and operation. In the end, solving these problems is necessary to ensure the efficient interoperability of future Trans-European High-Speed Rail Network. In this context, significant projects, particularly in the field of high-speed railways, are being developed within the framework of ecological approaches in our country, our region and across the globe. As stated, the current debates on the railway from the environmental perspective continue over the rail-borne noise. However, road transportation projects and air transportation projects are also being extensively assessed in the context of environmental approaches in different phases.

Depending on the extensiveness of the railway operating systems, a hierarchically-structured planning process is usually implemented in the production and follow-up of train schedules. In a railway network system, the basic structure of a train schedule is the identification of a track plan which calculates the number of trains serving on a line connecting two terminal stations within a fixed time interval. For a rail line which is not divided into phases, passenger train planning is basically concerned with calculation of stop-and-go charts for an entire trip plan.

Despite its proven advantages, the zone-based stop-and-go approach is not feasible for railway lines, except for suburban commuter transportation systems. The reason for this is that typical zoning representations are specifically adapted for a rail line where the majority of the passenger volume is produced or withdrawn at one or more stations in the city center.

\section{Planning of High-Speed Train Passenger Service}

High-speed train (HST) systems are considered as an intercity passenger transportation mode on selected routes and corridors of up to $800 \mathrm{~km}$. High-speed train (HST) operation requires a more coordinated planning than conventional railway systems since it provides passenger services in a higher volume and frequency. High-speed train (HST) travel in the context of train planning requires efficient planning by an optimized model [9]. The precise planning decisions regarding the provision of passenger train services on an intercity high-speed train (HST) line require a hierarchical structure.

A plan is used as a basic guideline for supporting operational decisions in daily train operations. The table below provides the start-up costs for various high-speed train projects. 


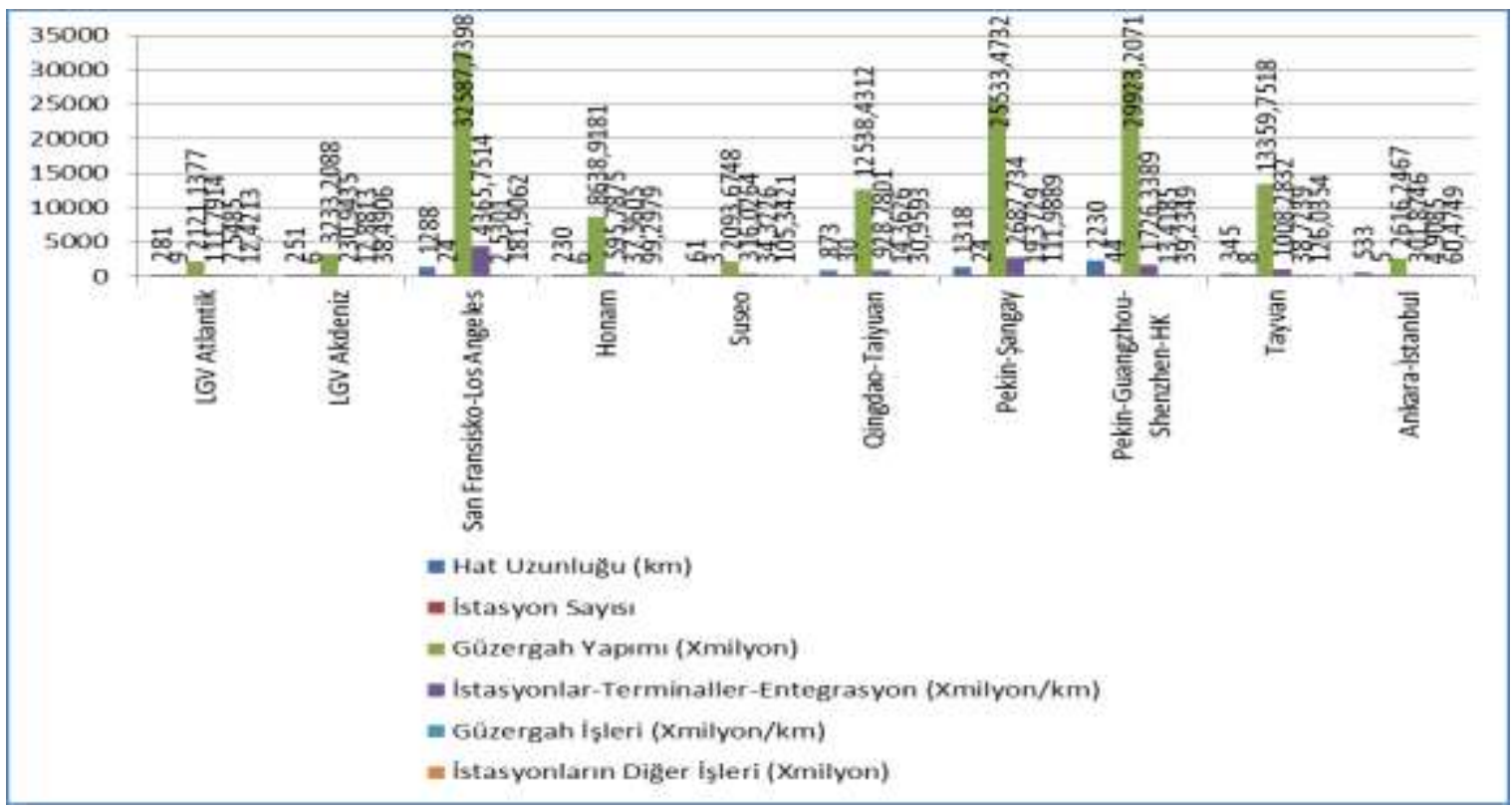

Table 2. Start-up Costs of Various High-Speed Train Projects [9]

Legend:

\begin{tabular}{|l|l|}
\hline Hat Uzunluğu & Track Length \\
\hline İstasyon sayısı & Number of stations \\
\hline Güzergah yapımı (xmilyon) & Construction of a line route (xmillion) \\
\hline İstasyonlar-Terminaller-İntegrasyon & Stations-Terminals-Integration \\
\hline Güzergah İşleri & Route Works \\
\hline İstasyonların Diğer İşleri & Other Station Works \\
\hline
\end{tabular}

Effective planning in provision of passenger services requires a balanced supply and demand. In terms of demand, passenger satisfaction is the key to successful operation of the rail service. Apart from safety and comfort factors, the primary interest of passengers in the selection of rail travel is reliability. Reliability is related to frequency of service and trip time. On a rail line that is not divided into phases, the travel time of the passengers usually consists of dwell times, driving times and stop-and-go times of train. In the tactical planning model for the calculation of optimal train stop and go charts, only the stop-and-go times of the train should be taken into consideration to reflect the trip time loss of the passengers. Evidently, a composition of various types of service is provided based on a stop-and-go chart for a train which can establish the optimized balance between the required minimum operating cost and minimum trip time loss. Table 3 below provides the economic assessments of HS2 high-speed train line in the United Kingdom. 


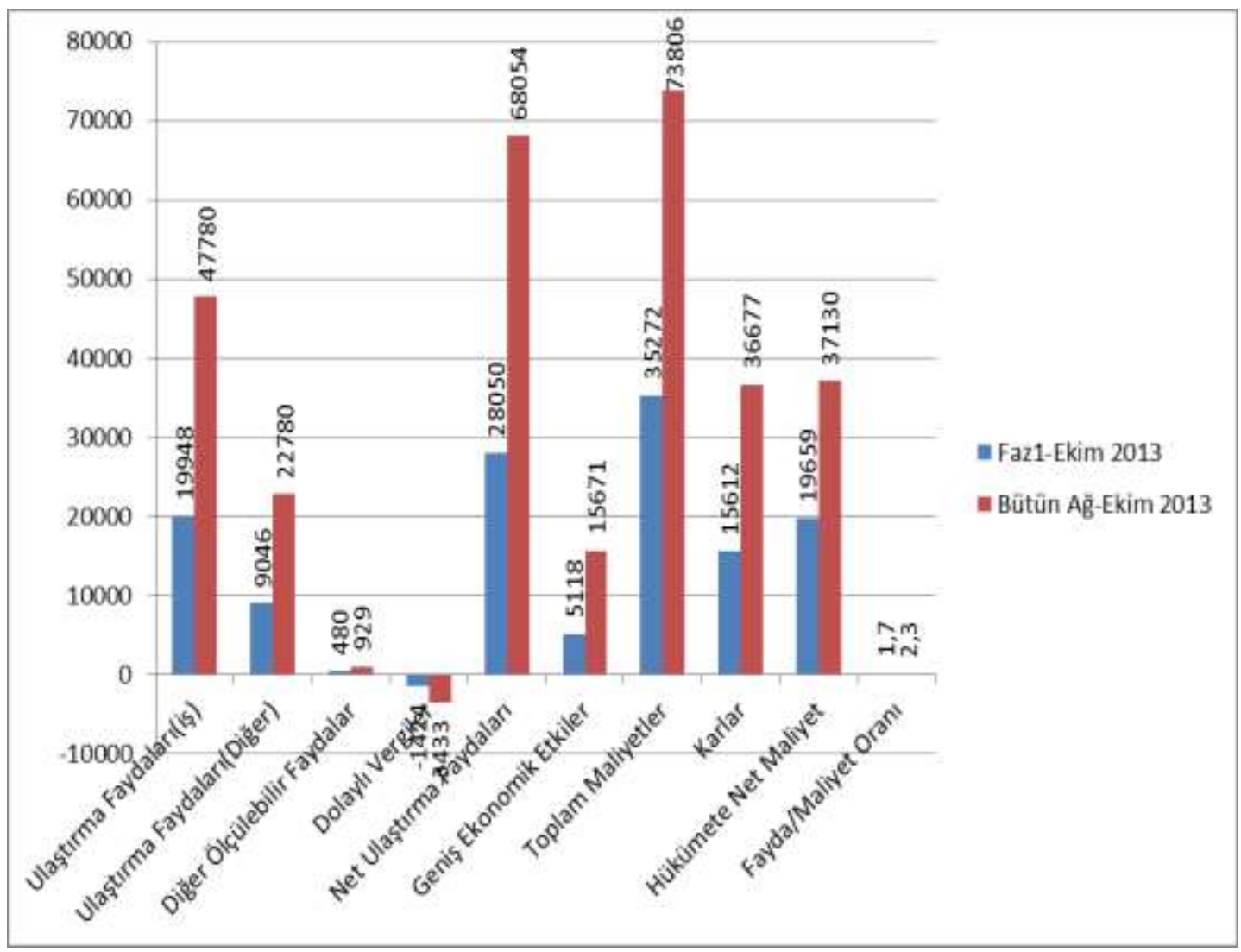

Table 3. Current Values of Costs and Benefits over a Period of 60 Years (million Euro) [9]

Legend:

\begin{tabular}{|l|l|}
\hline Faz1-Ekim 2013 & Phase1-October 2013 \\
\hline Bütün Ağ-Ekim 2013 & Entire Network - October 2013 \\
\hline Ulaştırma Faydaları (İs) & Transportation Benefits (Work) \\
\hline (Diğer) & (Other) \\
\hline Diğer Ölçülebilir Faydalar & Other Measurable Benefits \\
\hline Dolaylı Vergiler & Indirect Taxes \\
\hline Net Ulaştırma Faydaları & Net Transportation Benefits \\
\hline Geniş Ekonomik Etkiler & Broad Economic Effects \\
\hline Toplam Maliyetler & Total Costs \\
\hline Karlar & Profits \\
\hline Hükümete Net Maliyet & Net Cost on Government \\
\hline Fayda/Maliyet Oranı & Benefit/Cost Ratio \\
\hline
\end{tabular}

\section{Conclusions}

In terms of supply, the railway operator may request minimization of the entire operating cost. It can be achieved according to a train service plan with an optimum distribution of the minimum required trip times of the train in order to meet the transportation demand. In order to balance the requirements between the operator and the 
passenger, two planning purposes are taken into consideration: (a) minimization of the total operating cost for the operator and (b) minimization of the total trip time loss of the passengers. The operating cost of a train trip consists of a fixed overhead cost and a changing cost depending on the travel distance. Total operating cost of the operator is defined as the sum of the fixed and changing operating costs of all train trips required to meet the travel demand. For passengers, if a train stops at an interim station where passengers do not board or alight the train, there is a loss of travel time. Total travel time loss of passengers is defined as the sum of the time lost during the stops at the interim stations for all passengers serviced in all train trips. The two conflicting planning goals are generally affected by stop-and-go charts.

Effective planning of passenger train services must take into account the needs of both the operator and the passenger. Within the scope of such studies, a multi-purpose programming model is introduced for both minimizing the total operating cost for the operator and minimizing the total trip time loss for the passenger.

\section{References}

1. Ilıcalı, Mustafa, 'Yüksek Hızlı Demiryolları, Ulaştırmadaki Yenilikler ve Türkiye', Taşıma Dünyası, 2014: 4

2. Ampe, F., Technopole development in Euralille, in: D. Banister (Ed.) Transport and Urban Development, 1995: 115.

3. Anderson, J., Government ends scoping study on east coast very high speed train network. Media release by The Hon. Johan Anderson MP, Australian Deputy Prime Minister, Minister for Transport and Regional Services, 2002: 2

4. Bouley, J., Innovative areas: high speeds, in: ECMT, European Conference of Ministers of Transport, European Dimension and Future Prospects of the Railways (Paris: ECMT); 1986: 2.

5. Assad, A.A., 1980b. Modelling of rail networks: toward a route/makeup model. Transportation Research 14 B, 101-114.

6. Bowerman, R., Hall, B., Calamai, P., 1995. A multi-objective optimization approach to urban school bus routing: Formulation and solution method. Transportation Research 29A, 107-123.

7. Bussieck, M.R., Kreuzer, P., Zimmermann, U.T., 1997a. Optimal lines for railway systems. European Journal of Operational Research 96, 54-63.

8. Bussieck, M.R., Winter, T., Zimmermann, U.T., 1997b. Discrete optimization in public rail transport. Mathematical Programming 79, 415-444.

9. Schulte-Werning, B., Matschke, G., Willaime, A., Malfatti, A., Mancini, G. and Pecorini, M. High speed trains with bogie fairings: European research into reducing aerodynamic drag and noise. In Proceedings of the World Congress on Railway Research (WCRR '99), Tokyo, Japan, 1999. 